\title{
Family Background, Parent-child communication and Children's Academic Outcomes in China: Empirical Analysis Using Data from CPFS 2018
}

\author{
Tianyang Miao ${ }^{1, *}$ \\ ${ }^{1}$ Shenzhen Senior High School Shenzhen City Guangdong Province P.R. China \\ *1134664396@qq.com
}

\begin{abstract}
Studies of education stratification in China has not investigated the roles of family SES and parent-child communication styles in children's academic achievement. Using data from China Family Panel Studies (CFPS) of 2018, the study focuses on how parent's communication affect children's academic performance net of the influence of family SES, and whether parent's communication style absorbs part of the association between parent's education value and children's academic performance. Empirical results from multivariate regressions reveal a larger effect of parent's proactive communication on children's Chinese and Math performance, compared to the associations between family SES and children's outcomes. Besides, parent's proactive communication absorbs nearly all effect of parent's higher educational value on children's academics. Given that large mediation effect, it is likely that parents who care more about education can mainly boost the children's academic outcomes via improved communications, rather than other mechanisms. The study challenges past research of educational stratification in China which solely stress on material mechanisms, such as educational expenditure.
\end{abstract}

Keywords: Family Social Economic Condition, Education Stratification, Parent-child communication, Parent Educational Values

\section{INTRODUCTION}

Family background has played important roles in shaping children's educational performance, which is shown by many empirical research based on Western countries [1][2][3]. Not only that family background has a long-arm impact on a child's educational attainment and status attainment, the social-economic resources of the parents can also shape the developmental outcomes of children when they are younger, or during school ages [4][5]. Apart from the higher material and interpersonal support, parents of high SES families may also adopt different parenting styles due to the different parents' cultural capital and social capital [6][7]. Therefore, family SES can shape the children's development via the mediation of parenting styles. Despite the rich literature on family Social-economic Status (SES) based on western contexts, few studies investigate the relationships among family SES, parenting styles and children's development outcomes in China [8].
The education system of China has been known for being highly standardized but is increasingly stratified in which family SES plays an important role in perpetuating the stratification [8][9]. In recent decades, higher education has been expanded in China, allowing a growing number of students to attend college and achieve a higher educational level. Although the Chinese college-entrance exam is highly standard, the equalizing role of collegeentrance exam is increasingly limited. Indeed, elite colleges featuring 985 or 211 are increasingly selective due to the expansion of the number of students taking the Gaokao exams every year [10]. As a result, upper middle-class parents adopt more "concerted cultivation" approach in parenting to either boost the chances of their children of attending elite Chinese colleges or colleges in Western countries. Some strategies include increasing educational investment and adopting more proactive communication with the children to strengthen their awareness and conscientiousness. While educational investiment represents a material pathway, parent-child communication style reflects the different cultural practice within a family. 
This paper focuses on the following questions which are not sufficiently addressed in the past literature. 1) How does different dimensions of family SES associate with children's academic performance in contemporary China? 2) How do parent's educational attitude (stress on educational value) and communication style (more proactive communication) affect children's academic performance net of the influence of family SES? 3) Whether parent's communication style absorbs part of the effect of parent's education attitude on children's academic performance net of family SES?

The analysis draws on China Family Panel Studies (CFPS) of 2018 and children aged between 6 and 16 at the survey time to investigate the relationships between family SES and conditions (including income, wealth, house ownership, urban/rural hukou, parents' length of coresidence), parent educational attitude (the extent parent care about children's education), parent's communication style (whether parent adopts a proactive communication styles) and children's developmental outcomes (Chinese academic performance, math academic performance). Multivariate analyses are adopted to test the hypothesis that 1) a higher family SES is positively correlated with children's academic outcomes, such as Chinese and math performance, 2) the parent's educational attitude and proactive parenting practice have a positive association with children's outcomes net of the impact of family SES, and 3) parent proactive communication may absorb part of the effect of parent's education attitude on children's academics. The results confirm all three hypotheses.

The results hinge on the importance of parenting practice and parent-children relationship quality on children's attainment, departing from past literature which solely emphasized on the role of material conditions of families in intergenerational mobility. Overall speaking, the study sheds new lights on the mechanisms of family inequality of children's educational achievement in China, which implies on parent-children communication and parenting practices as important targets of policy interventions which aim at promoting education equality and intergenerational mobility in China.

\section{LITERATURE REVIEW}

\subsection{Family SES and education stratification in China}

There has been an expansion of higher education in China, which offered more opportunities for younger generations. Past sociological research contends that college is an equalizer of social inequality [4][5]. That is, as long as children receive college education, their labor market opportunities are essentially the same. However, the theory assumed that children's chance of entering college should be independent of their family
SES. In fact, college attainment, and especially elite college attainment is highly unequally distributed across children of different family SES background. For instance, the acceptance rate of " 211 " colleges in China has been extremely low[10]. Family background has played a large role in deciding whether the children can go to an elite college. Children's academic performance is an early indicator of where the children's can end up locating on the educational hierarchy. Therefore, it is important to better understand how family SES affects children's academic performance.

\subsection{Parent educational attitude, parent-child communication, and Children 's outcomes}

Past research based on the context of China has mainly focused on material investment as the key mechanism of educational stratification across different family background. However, little attention has been paid to parent-child communication, and children's outcomes. Li and Qiu (2018) is an exception which finds that both family resources and parent involvement in educational related activities can affect children's academic outcomes. However, they haven't not examined the relationship among parent educational value, parent-child communication and children's academic outcomes. Compared to western parents, such as those in the US or West European countries, Chinese parents are more likely to adopt an authoritarian parenting style (compared to authoritative, negligence and indulgent) or a combination of authoritarian parenting style with an emphasise on the idea of "training" [11]. Based on child-development theory and social-psychological theories, two hypotheses are proposed in the study: 1) both parent's education attitude (higher emphasis on education) and parent proactive communication can affect children's outcomes positively, and 2) the effect of parent's educational attitude may be mediated by parent communication to affect children's outcomes

\subsection{Family background and parent-child relationship}

Family SES might be correlated with higher parent's value on education, reflected by either more efforts devoted in communication or providing more educational resources. However, it is unclear whether the material conditions or the communication aspect is more important in transmitting parent's educational value on children's academic performance. Parents with a higher education value may either purchase more and provide access to more stimulative activities, or they can adopt a more proactive approach of communication with the children. Proactive communication may include concerted rolemodelling, storytelling and intensive socialization. Family SES may be important confounder which affects both the 
material conditions and communication aspects, as well as the children's academic performance. High SES parents may be able to afford more material resources, and may adopt a more proactive communication style given that they are more likely to be highly educated. Therefore, it is important to control for family SES and to examine the importance of parent's proactive communication in mediating parent's educational value on children's outcomes.

\section{RESEARCH DESIGN AND METHODS}

The study uses multivariate regression analysis to test the relationships among family SES, parenting practices and children's developmental outcomes. First, I specify a baseline model which only includes family SES:

$y_{i}=\beta_{0}+\beta_{1}$ family $_{\text {SES }}+e_{i}$

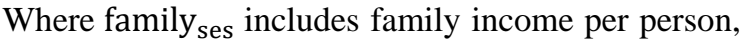
hukou status(rural/urban), family asset, homeownership, and the children's demographic information such as gender, and age. Children may have different developmental trajectory across ages, so it is reasonable to compare the performance within the same birth cohort of children. Therefore, dummies of children's age are included in all the models. Each of the models are estimated for children's Chinese and math performance separately.

Based on model (1), I further test whether the lengths of parental coresidence would additionally explain the difference in children's outcomes, net of family SES:

$y_{i}=\beta_{0}+\beta_{1}$ family $_{\text {SES }}+\beta_{2}$ Mom $_{\text {coresidence }}+$ $\beta_{3} \operatorname{Dad}_{\text {coresidence }}+\mathrm{e}_{\mathrm{i}}$

(2)

Where Mom_coresidence and Dad_coresidnece both are indicators of lengths of parental coesidence with the child in the past survey year.

Based on model (2), I further consider the impact of family parenting practices by adding two variables into equation (2), parent's self-reported attitude of education, and parent's communication with the child, separately and jointly.

$y_{i}=\beta_{0}+\beta_{1}$ family $_{\text {SES }}+\beta_{2}$ Mom $_{\text {coresidence }}+$

$\beta_{3}$ Dad $_{\text {coresidence }}+\beta_{4}$ Care_edu $+\mathrm{e}_{\mathrm{i}}$

(3)

$\mathrm{y}_{\mathrm{i}}=\beta_{0}+\beta_{1}$ family $_{\mathrm{SES}}+\beta_{2}$ Mom $_{\text {coresidence }}+$ $\beta_{3}$ Dad $_{\text {coresidence }}+\beta_{5}$ Active_commu $+\mathrm{e}_{\mathrm{i}}$

(4)

$\mathrm{y}_{\mathrm{i}}=\beta_{0}+\beta_{1}$ family $_{\text {SES }}+\beta_{2}$ Mom $_{\text {coresidence }}+$

$\beta_{3}$ Dad $_{\text {coresidence }}+\alpha$ Care_educ $_{\mathrm{i}}+\theta$ Active_commu $_{\mathrm{i}}+$ $\mathrm{e}_{\mathrm{i}}$
The coefficients of $\beta_{4}$ and $\beta_{5}$ are of key interest, which represent the net associations of parent's educational attitude, Care_edu (whether or not the parent care about child's education), and communication style, Active_commu (whether the parent adopt a proactive a proactive communication style) with the child's developmental outcomes in terms of Chinese and math performance. I include both Care_educ and Active_commu in model (5) to investigate whether one of the indicators may explain part of the effect of the other, say whether the effect of parent's educationaal attitude is mediated by parent's communication style to affect the children's development.

\section{DATA AND MEASURES}

This study uses the data from 2018 China Family Panel Studies (CFPS), which is a longitudinal survey data collected by Peking University. CFPS covers a rich set of information including the residential, demographic, social economic characteristics of Chinese. The data also covers people's self-reported evaluation of communication quality, values of education, and children's academic performance. The survey covers 15,000 families and around 30,000 individuals in the baseline wave of 2010, and the same people were followed annually. To test the research questions proposed, I use the data of CFPS 2018. The sample is constructed by merging the child proxy file and family social-economic file and is selected based on the non-missing cases of all the key variables under study $(\mathrm{N}=3101)$.

The children's demographic characteristics include gender and age. Important measures of family SES include household income per capita, family asset, urban/rural Hukou, and the family's homeownership (own or rent). Measures of parent-child relationship include the duration of the father's and mother's coresidence with the child in the past year (less than 6 months, 6 months to 11 months and 12 months), the parent's reported degree of caring of the children's education and the extent that parents communicate the child in a proactive manner. Children's academic outcomes are measured by the Chinese and math performance reported by the parents.

\section{RESULT}

For the sake of parsimony, the sample descriptive statistics are not presented (Available upon request). In general, the sample of analysis include 3101 cases of Chinese children aged from 2 to 16 years old with $47 \%$ of girls and $53 \%$ boys. Their average per capita family income is around 18,460 RMB, and family's total asset is averaged at $644,024 \mathrm{RMB}$. Around $60 \%$ of the 
children have a rural Hukou, and $40 \%$ have urban hukou. Around $88 \%$ of all households own their house.

As rural children represent for a large proportion of the sample, the length of coresidence between parents and children can vary to a large extent, unsurprisingly. Around $29 \%$ of children coreside with mothers for less than 6 months, $7 \%$ between 6 and 11 months, and only $64 \%$ of children have mothers present for a full year in the past year. Compared to mothers, fathers tend to live with the children even shorter. Among all children, around $42 \%$ children have fathers present for less than 6 months, around $10 \%$ between 6 and 11 months and $48 \%$ for a full year.

In contrast to the common impression of Chinese Confucius norms stressing on education, the extent that parents care about the children's education vary extensively. While around $45 \%$ parents disagree or remain neutral about the statement that they care about children's education, $55 \%$ agree. Similar to parent's educational attitude, parent's communication style also vary greatly; that is around $36 \%$ and $64 \%$ of parents disagree and agree that they adopt a proactive communication style with the child.
The outcome variables are the parents' reported children's Chinese and math academic performance. Around $44 \%$ children were reported to have good performance in Chinese, and $55 \%$ were underperformed. While around $43 \%$ children were reported to perform well in math, $56 \%$ were underperformed.

Table 1 shows the multivariate regression results as shown in equation 1 and 2. As is shown by column (1), family asset is positively associated with Chinese performance although the coefficient is substantively small. Boys perform worse in Chinese than girls, with a 9\% lower probability of demonstrating good Chinese performance. Duration of coresidence with either the fathers or the mothers do not associate with children's Chinese performance after controlling for family SES, as is shown in Column (2). By contrast, math outcome is significantly correlated with length of coresidence with mothers, with those who live with the mothers in the same household for 12 months showing around 6\% higher probability of good math performance (Column 4). At the same time, children's urban hukou status is significantly and positively associated with children's math performance.

Table 1. Multivariate Linear Probability Model of Children's Developmental Outcomes on Family SES

\begin{tabular}{|c|c|c|c|c|}
\hline & (1) & (2) & (3) & $(4)$ \\
\hline & Chinese & Chinese & Math & Math \\
\hline \multirow[t]{2}{*}{ Family income per person } & -0.00020 & -0.00020 & -0.00010 & -0.00010 \\
\hline & $(0.00)$ & $(0.00)$ & $(0.00)$ & $(0.00)$ \\
\hline \multirow[t]{2}{*}{ Urban Hukou } & 0.02317 & 0.02100 & $0.059^{\star *}$ & $0.048^{*}$ \\
\hline & $(0.02)$ & $(0.02)$ & $(0.02)$ & $(0.02)$ \\
\hline \multirow[t]{2}{*}{ Homeownership } & 0.00182 & 0.00177 & 0.01505 & 0.01363 \\
\hline & $(0.03)$ & $(0.03)$ & $(0.03)$ & $(0.03)$ \\
\hline \multirow[t]{2}{*}{ Total Family Asset } & $0.00002^{\star * *}$ & $0.00002^{* * *}$ & $0.00002+$ & $0.00002+$ \\
\hline & $(0.00)$ & $(0.00)$ & $(0.00)$ & $(0.00)$ \\
\hline \multirow[t]{2}{*}{ Gender(male) } & $-0.094^{* * *}$ & $-0.096^{* * *}$ & -0.007 & -0.009 \\
\hline & $(0.02)$ & $(0.02)$ & $(0.02)$ & $(0.02)$ \\
\hline \multicolumn{5}{|c|}{ Coresidence with Mother (ref: coreside for less than 6 months) } \\
\hline \multirow[t]{2}{*}{ 6-11 months } & & -0.024 & & -0.022 \\
\hline & & $(0.04)$ & & $(0.04)$ \\
\hline \multirow[t]{2}{*}{12 months } & & 0.019 & & $0.056^{*}$ \\
\hline & & $(0.03)$ & & $(0.03)$ \\
\hline \multicolumn{5}{|c|}{ Coresidence with Father (ref: coreside for less than 6 months) } \\
\hline \multirow[t]{2}{*}{ 6-11 months } & & 0.0167 & & 0.010 \\
\hline & & $(0.04)$ & & $(0.04)$ \\
\hline \multirow[t]{2}{*}{12 months } & & 0.012 & & 0.010 \\
\hline & & $(0.02)$ & & $(0.02)$ \\
\hline \multirow[t]{2}{*}{ Constant } & $0.805^{\star \star \star}$ & $0.790^{\star \star \star}$ & $0.714^{* \star *}$ & $0.677^{\star \star *}$ \\
\hline & $(0.21)$ & $(0.21)$ & $(0.21)$ & $(0.20)$ \\
\hline $\mathrm{N}$ & 3101 & 3101 & 3101 & 3101 \\
\hline
\end{tabular}

Notes: Robust standard errors in parentheses. $+\mathrm{p}<0.1,{ }^{*} \mathrm{p}<0.05, * * \mathrm{p}<0.01,{ }^{*} * \mathrm{p}<0.001$

Dummies of child's age group are controlled for. 
Table 2. Multivariate Linear Probability Model of Children's Developmental Outcomes on Family SES and Parenting Practices

\begin{tabular}{|l|l|l|l|l|l|l|}
\hline & $(1)$ & $(2)$ & $(3)$ & $(4)$ & $(5)$ & $(6)_{-}$ \\
\hline & Chinese & Chinese & Chinese & Math & Math & Math \\
\hline $\begin{array}{l}\text { Care About Child's Education (reference: } \\
\text { don't care) }\end{array}$ & & & & & \\
\hline Care & $0.05931^{* * *}$ & & 0.02736 & $0.03889^{*}$ & & 0.00607 \\
\hline & $(0.02)$ & & $(0.02)$ & $(0.02)$ & & $(0.02)$ \\
\hline $\begin{array}{l}\text { Parent communicate with the child } \\
\text { (reference: Passive communication) }\end{array}$ & & & & & & \\
\hline Active communication & & $0.07365^{* * *}$ & $0.05478^{*}$ & & $0.06044^{* * *}$ & $0.05625^{*}$ \\
\hline & & $(0.02)$ & $(0.02)$ & & $(0.02)$ & $(0.02)$ \\
\hline Constant & -0.04105 & -0.05730 & $-0.06368+$ & 0.21444 & 0.19262 & 0.19120 \\
\hline & $(0.04)$ & $(0.04)$ & $(0.04)$ & $(0.26)$ & $(0.26)$ & $(0.26)$ \\
\hline $\mathrm{N}$ & 3101 & 3101 & 3101 & 3101 & 3101 & 3101 \\
\hline
\end{tabular}

Notes: Robust standard errors in parentheses. $+\mathrm{p}<0.1,{ }^{*} \mathrm{p}<0.05, * * \mathrm{p}<0.01, * * * \mathrm{p}<0.001$

Dummies of child's age group are controlled for. All models control for family SES measures, including family income per person, Hukou, homeownership, total family assert, coresidence with mother, coresidence with father and gender. Coefficients of these family SES measures are not reported for parsimony.

Table 2 reports results corresponding to Equation 3-5 in the analytical strategy section, in which parent's educational attitude and communication style are also included based on Equation 2. The results are remarkably consistent across children's Chinese and math performance. As shown by the first two columns of Table 3, children's chance of having a good Chinese performance is increased by around $6 \%$ in cases where parent respondent reports caring about the children's education. Parent's active communication is associated with an $7 \%$ increase of the chance of their children having good Chinese performance, demonstrating a larger effect than the effect of family SES on children's academic performance. After including both parent's educational attitude and communication style into the model, however, the association of parent educational attitude and children's Chinese academic performance becomes statistically insignificant, with active communication demonstrating positive and significant associations of around $5 \%$ with Chinese performance of the children (as is shown by Column 3). As for the results of children's math performance, parent educational attitude and active communication both increase the chance of children having good math performance by $4 \%$ and $6 \%$ when the two independent variables are included in the multivariate models separately. Interestingly, when parent educational attitude and active communication are both in the model, only active communication is positively and significantly associated with children's math performance but not parent educational attitude. The results imply for a possible mediation channel of parent communication style underplay which connects parent educational attitude with children's academic performance. That is: parents who care about children's education may be more likely to adopt a proactive communication style, and such communication style can benefit the children's academic performance.

\section{DISCUSSION}

There are several limitations of the current study. First, children's Chinese and math academic performance are self-reported by the parents. Therefore, the reporting biases cannot be ruled out, that it is possible that parents who stress more on education and communication are also more likely to report better performance of their children. Future study may use standardized test scores of children as measure of academic performance to reduce such reporting biases. Second, as mentioned above, although the study implies on the relative importance of parent communication as a mediator of parent's educational attitude on children's academic performance, other possible mechanisms, such as material conditions, are not included in the analysis so far. Since educational expenditures are accessible in the dataset, I plan to investigate this aspect as an extension of this current research. Third, the current study has a limited set of controls of family SES measures. Some other important dimensions, such as parent's education and occupations, should be included in the next step analysis.

\section{CONCLUSION}

Using the data of CFPS 2018 and multivariate linear probability models, the paper have three findings regarding the relationships among family SES, 
parenting practices and children's academic outcomes. First, family SES constrains children's academic performance of both Chinese and Math in China, although its significance and mechanisms seem to differ for the two subjects. Specifically, family asset is positively associated with both Chinese and math performance, urban hukou status and the duration of mother's coresidence are associated with a higher math score of children, with the latter two factors not significantly contributing to children's Chinese performance. Second, parent's reported educational attitude (a higher extent of care about the children's education) and a proactive communication approach are positively associated with reported children's Chinese and math learning outcomes in separate models, net of the associations of family asset, family income, children's Hukou status, the family's homeownership, children's gender, father and mother's duration of coresidence, and the dummies of children's age. Once parental education attitude or communicating style are controlled for, the partial correlation coefficients of family asset and mother's duration of coresidence reduced slightly, suggesting that parental education attitude or communicating style may explain part of the effect of family asset and mother's presence, but not Hukou status. Third, when both parent's education attitude and communication style are controlled for in the same model, only communication style appears to be significantly correlated with children's academic performance, but not parental education attitude, which is consistent for both Chinese and math outcomes. This implies that parent's education attitude mainly affects children's outcomes indirectly through parent's communication style. Parents who stress on children's education tend to adopt a more proactive communication style, which improves children's academic performance.

\section{AUTHORS' CONTRIBUTIONS}

Situated in the context of China, this paper addresses the gap of the literature of family SES and children's academic achievement by shedding lights on the role of parent-child communications. Past research has not looked at the role of parent's communication styles in shaping children's achievement among children of different SES background. This study found evidence that parent proactive communication styles have more significant effects on children's academic achievement than family SES measures, such as family asset. Besides, parent's proactive communication absorbs the effect of parent education attitude on children's academic performance to a large extent. Given that large mediation effect, it is likely that parents who care more about education can mainly boost the children's academic outcomes via improved communications, rather than other mechanisms. The study challenges past research of educational stratification in China which solely stress on material mechanisms, such as educational expenditure. Overall speaking, the study contributes to the literature of educational stratification by emphasizing the roles of family processes and culture, such as parent-child communication styles.

\section{REFERENCES}

[1] Buchmann, C., \& DiPrete, T. A. (2006). The growing female advantage in college completion: The role of family background and academic achievement. American sociological review, 71(4), $515-541$

[2] Björklund, A., \& Salvanes, K. G. (2011). Education and family background: Mechanisms and policies. In Handbook of the Economics of Education (Vol. 3, pp. 201-247). Elsevier.

[3] Teachman, J. D. (1987). Family background, educational resources, and educational attainment. American sociological review, 548-557.

[4] Haller, A. O., \& Portes, A. (1973). Status attainment processes. Sociology of education, 5191.

[5] Sewell, W. H., \& Hauser, R. M. (1972). Causes and consequences of higher education: Models of the status attainment process. American Journal of Agricultural Economics, 54(5), 851-861.

[6] Lareau, A. (2011). Unequal childhoods. University of California Press.

[7] Spera, C. (2005). A review of the relationship among parenting practices, parenting styles, and adolescent school achievement. Educational psychology review, 17(2), 125-146

[8] Li, Z., \& Qiu, Z. (2018). How does family background affect children's educational achievement? Evidence from Contemporary China. The Journal of Chinese Sociology, 5(1), 121.

[9] Yeung, W. J. J. (2013). Higher education expansion and social stratification in China. Chinese Sociological Review, 45(4), 54-80.

[10] Wu, X. (2017). Higher education, elite formation and social stratification in contemporary China: Preliminary findings from the Beijing College Students Panel Survey. Chinese Journal of Sociology, 3(1), 3-31.

[11] Chao, R. K. (1994). Beyond parental control and authoritarian parenting style: Understanding Chinese parenting through the cultural notion of training. Child development, 65(4), 1111-1119. 